\title{
The use of insecticide-treated nets for reducing malaria morbidity among children aged 6-59 months, in an area of high malaria transmission in central Côte d'Ivoire
}

Benjamin G Koudou ${ }^{1,2,3^{*}}$, Hala Ghattas ${ }^{4,5}$, Clémence Essé2, ${ }^{2,6}$, Christian Nsanzabana ${ }^{2,7,8}$, Fabian Rohner ${ }^{2,9}$, Jürg Utzinger ${ }^{7,8}$, Brian E Faragher ${ }^{10}$, Andres B Tschannen ${ }^{2}$

\begin{abstract}
Background: Long-lasting insecticidal nets (LLINs) are an important tool for controlling malaria. Much attention has been devoted to determine both the effect of LLINs on the reduction of Plasmodium infection rate and on clinically-confirmed malaria cases in sub-Saharan Africa. We carried out an epidemiological study to investigate whether LLINs impact on Plasmodium prevalence rate and the proportion of clinically-confirmed malaria cases, in five villages in the district of Toumodi, central Côte d'Ivoire.
\end{abstract}

Methods: From April 2007 to November 2008, a community-based malaria control programme was implemented in the study villages, which involved large-scale distribution of LLINs, and training and sensitization activities within the community. We determined the effect of this programme on Plasmodium prevalence rate, clinically-confirmed malaria cases and proportion of high parasitaemia rates in children aged 6-59 months through a series of crosssectional surveys starting in April 2007 and repeated once every 6 months.

Results: We observed a significant decrease in the mean P. falciparum prevalence rate from April 2007 to April 2008 ( $p=0.029$ ). An opposite trend was observed from November 2007 to November 2008 when P. falciparum prevalence rate increased significantly $(p=0.003)$. Highly significant decreases in the proportions of clinical malaria cases were observed between April 2007 and April 2008 ( $p$ < 0.001), and between November 2007 and November $2008(p=0.001)$.

Conclusions: Large-scale distribution of LLINs, accompanied by training and sensitization activities, significantly reduced Plasmodium prevalence rates among young children in the first year of the project, whereas overall clinical malaria rates dropped over the entire 18-month project period. A decrease in community motivation to sleep under bed nets, perhaps along with changing patterns of malaria transmission, might explain the observed increase in the Plasmodium prevalence rate between November 2007 and November 2008.

\section{Background}

In Côte d'Ivoire, malaria remains the primary cause of health seeking at dispensaries, particularly during and shortly after the rainy season (from approximately midAugust to mid-October), accounting for $42 \%$ of all visits [1]. Moreover, malaria is the leading cause of

\footnotetext{
* Correspondence: g.b.koudou@liv.ac.uk

'Vector Group, Liverpool School of Tropical Medicine, Pembroke Place, Liverpool L3 5QA, UK

Full list of author information is available at the end of the article
}

hospitalization $(70 \%)$ and mortality $(15 \%)$, as recorded at paediatric units of hospitals [1].

With regard to malaria prevention, insecticide-treated nets (ITNs) have a track record of reducing malariarelated morbidity and mortality [2], and hence are increasingly being utilized in sub-Saharan Africa and other malaria-endemic areas. For example, sleeping under an ITN can decrease severe malaria by $45 \%$, reduce premature birth rates by $42 \%$, and significantly lower allcause child mortality [3]. Unfortunately, in Côte d'Ivoire, 
ITN coverage is low (i.e. only $6 \%$ of children aged below 5 years slept under an ITN according to the 'multiple indicators cluster survey' carried out in 2006) [4], with most of the nets in use being 'untreated'. However, to remain effective, nets need to be re-treated after several months, but re-treatment requires additional skills, and technical knowledge together with affordable products and community participation [5]. Inadequacy of these and other factors may hamper the expansion of largescale programmes involving insecticidal nets, and hence re-impregnation rates remain low and the nets become ineffective [6]. Consequently, several types of long-lasting insecticidal net (LLIN) treatments have been developed and evaluated in a wide range of situations [7].

Research carried out in rural Tanzania showed that a social marketing campaign with key messages and products readily adapted to the local settings can boost the coverage rates of ITNs, result in significant health gains and represents a cost-effective intervention to prevent malaria-related death [8-10]. In view of these findings and given the low coverage rates of ITNs in Côte d'Ivoire, we were motivated to implement a communitybased malaria control programme comprising of selective and mass distribution of LLINs in a highly endemic area of central Côte d'Ivoire [11]. In an initial evaluation, we assessed the exact number of households and age distributions of the population living in the study area. Common knowledge and perceptions pertaining to malaria prevention and use of LLINs were determined by using socio-anthropological surveys to collect baseline information prior to net distribution. Community health workers (CHWs) were trained to help mothers or caregivers to manage uncomplicated malaria cases and to sensitize community members on the advantages of sleeping under a LLIN. Of note, CHWs were carefully selected among the local community. They were proposed by village committees and issues of availability, commitment, honesty and willingness to participate were taken into account. CHWs were trained by community nurses in providing primary health care.

The goal of the project reported here was to reduce malaria morbidity in young children by promoting the use of LLIN within households, facilitated by CHWs. The study was implemented in five villages located in central Côte d'Ivoire that are characterized by the same climate and agricultural activities. We report a descriptive study with no defined control groups, using a 'before-after' evaluation design. Particular emphasis was placed on Plasmodium prevalence rate and the number of clinical malaria cases, determined by repeated crosssectional surveys. Plasmodium transmission by malaria vectors was investigated through entomological surveys in parallel to parasitological surveys with details presented elsewhere [12].

\section{Methods}

\section{Study area}

The study was conducted in five villages in the health district of Toumodi, in the commune of Djekanou in central Côte d'Ivoire: Tafissou-Bringakro (Taf-Bri), Gbohua-Angbavia (Gbo-Ang), Alluminankro-N'Kloidjo (All-N'Kl), N'Da Dibykro-N’Da Kouassikro (N’Da-N’Da) and Gbakokro-Abokro (Gba-Abo) (Figure 1). According to the house-to-house census carried out by interviewing heads of households in April 2007, the population of the target area was estimated at 7420 inhabitants.

The mean annual precipitation in this area is slightly above $1150 \mathrm{~mm}$, and the mean annual temperature is $26.5^{\circ} \mathrm{C}$. There are two seasons; a rainy season between April and October, and a dry season between November and March. The main activity in these communities is subsistence agriculture, supplemented with some cash crop, mainly consisting of cocoa, coffee and rubber production. The nearest health infrastructure is located in Taf-Bri, which is run by a nurse and three assistant nurses. Four of the villages have a primary school each (Taf-Bri, Gbo-Ang, N'Da-N'Da and Gba-Abo). At the time of our study, access to the power grid was available in two villages only (Taf-Bri and Gbo-Ang). Four villages had access to running water (Taf-Bri, Gbo-Ang, All-N'Kl and N'Da-N'Da).

Two entomological surveys were carried out in April and July 2008, after net distribution to householders. We recorded biting rates and entomological inoculation rates (EIRs) for Anopheles gambiae s.s., the main malaria vector in central Côte d'Ivoire [13-16]. The mean biting rates recorded were 1.5 and $4.1 \mathrm{bites} /$ person/night, in April and July 2008, respectively. The corresponding mean EIR recorded were 31.4 and 147.8 infective bites/ person/year in 2008. No mosquitoes from the species of An. funestus and An. pharoensis were found to be infected (BG Koudou, unpublished data).

The mean knock down (KD) and mortality rates recorded after performing standard World Health Organization (WHO) Pesticide Evaluation Scheme (WHOPES) tube bioassay tests in October 2008 with DDT, deltamethrin and permethrin on An. gambiae collected in this study area showed very high efficacy of these compounds. For example, we recorded a high KD rate with low fluctuations (range between $96.7 \%$ and $100 \%$ ) and also a high mortality rate (range between $91.6 \%$ and $100 \%)$. Hence, there is no indication of resistance among adult An. gambiae s.s mosquitoes in the study area.

\section{Ethical approval and informed consent}

Our study was approved by the Ivorian Ministry of Health through the national malaria control programme (NMCP). The heads of households in the study villages 


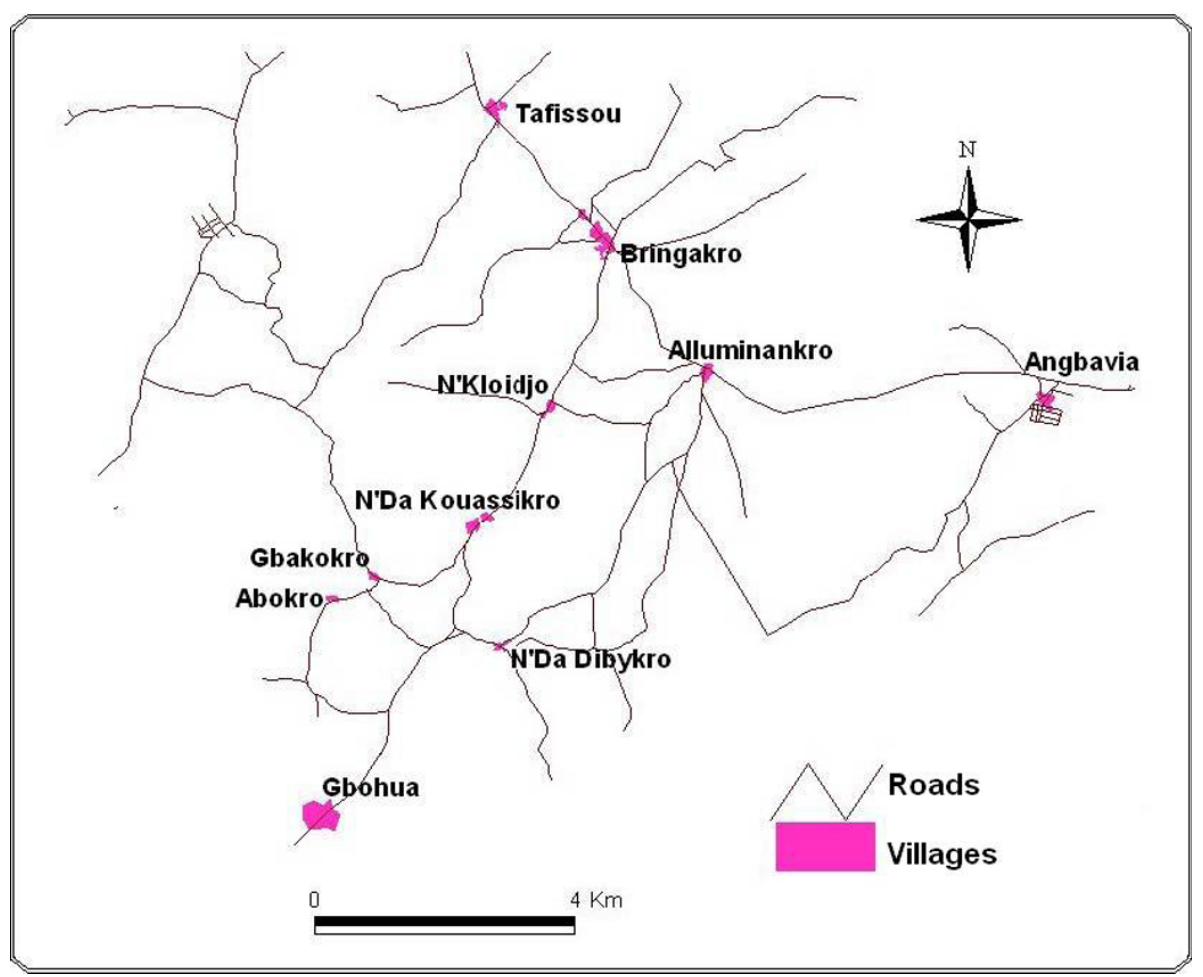

Figure 1 Location of the five study villages in the health district of Toumodi, central Côte d'Ivoire.

were informed about the objectives and procedures of the study and the parents or legal guardians of participating children gave written informed consent. Patients with malaria-related symptoms were treated free of charge according to the national malaria policy (i.e. artesunate plus amodiaquine) regardless of whether or not they participated in the cross-sectional surveys.

\section{Baseline evaluation}

In April 2007, in parallel with a cross-sectional clinical survey, a questionnaire was administered to the heads of households in the five villages. We employed a pretested questionnaire to obtain data on demographics (number of individuals living in a household, age, sex and religion), professional and economic activities of the adult population, assessment of construction material for walls and roofing of houses, connection to the power grid, and appraisal of wealth indicators based on the presence of various assets (e.g. bicycle, radio, etc.). Householders were interviewed about major health problems, preventive measures against mosquito bites (e.g. use of ITNs, fumigating coils, etc.), the availability of latrines, and disposal of wastewater and solid waste. Additionally, in May 2007, a total of 16 focus group discussions (FGDs) were conducted with young men and women, adults and older individuals in three of the study villages (Taf-Bri, Gbo-Ang and All-N'Kl).
Participants in the FGDs were recruited randomly with the help of CHWs. These FGDs centred on malaria causes and symptoms, and preventive measures employed against mosquito bites and commonly used antimalarial treatments.

Malariometric measurements were carried out in April 2007 before net distribution in the study villages to assess malaria parasitaemia and clinical cases in children aged 6-59 months. A finger prick blood sample was taken, thick and thin blood films were prepared on microscope slides and they were air-dried on the spot. The slides were transferred to a nearby laboratory and processed as detailed below.

\section{LLINs distribution and re-treatment of nets used during more than $\mathbf{3 0}$ months}

In July 2007, we received 3600 LLINs (PermaNet 2.0) from Vestergaard-Frandsen, of which approximately 2800 nets were distributed in the study villages. The remaining 800 nets were distributed in small hamlets ("campements") that surround the study villages. LLIN distribution started in early August 2007 and was continued until October 2008. Heads of households were encouraged to use the nets for children younger than 5 years of age in order to protect them from mosquito bites. In July 2007, in collaboration with the non-governmental organization Stop Malaria International 
(SMI), all nets previously in the area and used for more than 30 months were treated free of charge with a longlasting insecticide treatment (ICON MAXX; Syngenta Corporation). Heads of households were invited to send nets to a designated community location and the CHWs were trained by SMI to treat the untreated nets. Overall, 90 nets were treated according to the manufacturer's procedures.

\section{Sensitization and training activities Sensitization activities}

Subsequent to the initial evaluation, a series of sensitization campaigns (individual and mass sensitization) were conducted in each village. The aim of these campaigns was to improve knowledge on malaria transmission and preventive measures, and to increase acceptance of LLINs by the beneficiary communities. The activities started with a mass sensitization campaign that focused on the promotion of LLINs by the CHWs. In each village, CHWs held two meetings with the communities, during which everyone was invited to a designated location where the advantages of sleeping under a LLIN were explained and each householder received additional information to ensure that LLINs are used properly. Regular follow-ups were held in the intervention zones after net distribution. Communities were also informed about the importance of re-treating old nets. The sensitization campaign started in July 2007 and ended after reaching a high coverage level in March 2008 (i.e. more than half of children below the age of 5 years slept under a LLIN or a re-treated old net).

LLINs were ordered and packaged according to community preferences determined during an initial social survey carried out in April 2007. In agreement with village authorities, the CHWs were identified as net sellers. LLINs were sold at a low price (approximately US\$2, i. e. a third of the costs for a net in Côte d'Ivoire at the time of our study).

\section{Training activities}

Two training activities were carried out in June and August 2007. First, with the support of the NMCP and the regional health district, $\mathrm{CHWs}$ were trained on the causes of malaria transmission, preventive measures against mosquito bites and the management of uncomplicated malaria cases among children under the age of 5 years. Training focussed on the recognition of typical symptoms of uncomplicated malaria, as well as severe symptoms warranting referral to a nearby health centre. Secondly, the CHWs were also trained to perform a follow-up of severe malaria cases, to act as intermediaries between the health services and the community, and to provide advice to mothers/caregivers of under -5 yearold children on how to manage uncomplicated malaria cases. The activities related to mothers' and caregivers' practices and behaviours in response to malaria attacks were assessed by an MSc student specializing in socioanthropology who was in charge of this appraisal.

Antimalarial drugs (i.e. artemisinin-based combination therapy (ACT)) were kindly provided by a pharmaceutical company (Dafra Pharma; Turnhout, Belgium) and administered free of charge. Drugs were packaged in plastic bags labelled for one age group (0-59 months) according to standard recommendations by WHO. During the survey, children with measured fever (axillary temperature $>37.7^{\circ} \mathrm{C}$ ) and infected with $P$. falciparum were treated free of charge, and ACTs were given to CHWs to treat new uncomplicated malaria cases detected in agreement with the local nurse after the departure of our research team. CHWs kept drugs and supplied them to mothers/caregivers on demand for treating new uncomplicated malaria cases. CHWs supervised and monitored mothers' and caregivers' practices and behaviours directly by following them while they treated malaria cases that occurred in the household. A part of the money collected when nets were sold was used to assure that ACTs were available during the length of the study.

\section{Cross-sectional surveys}

Four repeated cross-sectional surveys were carried out in the study villages to assess malaria parasitaemia and clinical malaria in children aged 6-59 months. The surveys were done always in April and November, both in 2007 and 2008, i.e. once before the distribution of LLINs in August 2007 and three times afterwards. During the surveys, mothers and caregivers of under 5-yearold children were invited to accompany their children to a designated community location where a finger prick blood sample was taken from each child. Previously, all mothers who had one or several children below the age of 5 years were listed by the CHWs. During each crosssectional parasitological survey, previously selected children aged 6-59 months came to a designated place with their mothers or caregivers and the children were examined, adhering to a standard protocol.

In the laboratory, air-dried thick and thin blood smears were stained with Giemsa for $45 \mathrm{~min}$. Slides were examined by the same experienced laboratory technician throughout the study under a microscope at high magnification (x 100). Plasmodium species and gametocytes were identified and counted against 200 leucocytes. In case fewer than 10 parasites were found, the reading was continued for a total of 500 leucocytes. Parasitaemia was expressed by the number of parasites per $\mu \mathrm{l}$ of blood, assuming a standard count of 8000 leucocytes/ $\mu$ l blood. For quality control, $10 \%$ of the slides were randomly selected and re-examined by a senior laboratory technician. 
In our study, all children having an axillary temperature $>37.7^{\circ} \mathrm{C}$ were considered as fever cases. Clinical malaria was defined as fever plus parasitaemia [17]. In all cross-sectional surveys, a measurement of axillary temperature was taken from every child aged 6-59 months. Children with clinical malaria were treated with the first-line ACT antimalarial (i.e. artesunate plus amodiaquine) and paracetamol. High parasitaemia was defined as $>5000$ parasites/ $\mu$ l blood [15]. In each village, complicated malaria cases were referred to the nearest health centre with the help of the CHWs. During each cross-sectional survey, the mothers and caregivers of the children were interviewed about whether their children had slept under a LLIN the night before the survey. Before each survey, mothers and caregivers were invited to fill in and sign an informed consent form. The variation observed in the number of children examined is explained by the fact that during each survey, we examined children who were available and agreed to participate to the study.

\section{Follow-up of LLIN distribution campaign}

Every 2 months, the coordinator of the project had meetings with the CHWs in order (i) to assess the number of new LLINs sold and (ii) to evaluate the number of new LLINs installed in household sleeping rooms. The goal of these meetings was to assess the new bimonthly coverage rate of LLINs in each village, among children aged 6-59 months, and at the household level in general.

The monthly number of new LLINs sold was used to assess the overall number of LLINs sold. Additionally, every two months, CHWs assessed the number of LLINs installed and properly used in households. During the net promotion campaign, the number of LLINs sold per household was known because CHWs sold the LLINs only to heads of households. As the number of persons living in each household was determined beforehand, CHWs sold exactly the number of nets that were needed per household. Net coverage rates recorded in CHWs log-books were checked during two monitoring and evaluation visits in the study sites (April and October 2008).

\section{Statistical analysis}

Data were analysed in STATA version 9.0 (STATA Corporation; College Station, TX, USA). Monthly malaria prevalence rates were computed for April 2007, November 2007, April 2008 and November 2008 for each village separately and then for all villages combined. These rates are reported with their 95\% confidence intervals (CIs). As it was only possible to evaluate random samples of children in each village at each of the four assessment times, the CIs are finite population corrected (i.e. adjusted for the known population of each village). Overall monthly prevalence rates were compared before and after the distribution of the LLINs, using logistic regression models that were adjusted for the clustering of individuals within villages (by including village number as a dummy random variable, using the "cluster (village code)" subcommand in the "logistic" subroutine in Stata 9.0). To allow for known seasonal variation in malaria rates in the study area [16], comparisons were restricted to April 2007 vs. April 2008 and November 2007 vs. November 2008. No formal comparisons were made within individual villages as this was outside the remit of the study; differences between villages were adjusted for by treating these as clusters. Statistical significance was set at the conventional alpha $=0.05(5 \%)$ level.

\section{Results}

\section{Socioeconomic analyses and bed net use at baseline}

Table 1 presents the results of the initial survey carried out in all households $(n=717)$ in each of the five villages. Improved sanitation facilities (modern latrines and electricity) are not widely available in the study area.

The surveys showed a clear difference between reported ownership and net use. Though a third of households $(34.2 \%)$ possessed a net, only $3.2 \%$ of householder reported that they actually used these nets (corresponding to 237 persons). A common reason stated by adults for not using a net was that the nets were not felt appropriate. The proportion of children below the age of 5 years who slept under a net was low (14.2\%). With regard to personal protective measures against mosquito bites, fumigating coils was the most widely used tool (28.0\%). Approximately one out of seven households used insecticide sprays, mainly applied on walls and ceilings (15.2\%).

The preferred colour for the use of LLINs was blue; almost half of the interviewed households mentioned this colour (45.3\%), followed by green $(22.8 \%)$ and white (12.1\%). The preferred shape of LLINs mentioned by the households is rectangular (64.1\%). More than threequarter of the householders interviewed (77.1\%) agreed to pay F CFA 1000 (approximately US\$ 2), corresponding to one third of the LLIN price at the national public health pharmacy at the time of our study.

\section{Socio-anthropological qualitative analyses}

According to the FGDs, the main causes of malaria were the sun, tiredness due to field work and household work, inadequate nutrition, cold and constipation. Concerning the use of preventive measures against mosquito bites, the majority of respondents mentioned anti-mosquito measures such as ITNs, fumigating coils, modern and traditional insecticides. 
Table 1 Household characteristics and protective measures against mosquito bites in five study villages, central Côte d'Ivoire

\begin{tabular}{|c|c|c|c|c|c|c|}
\hline Socioeconomic indicators & Study village & & & & & Overall \\
\hline & $\begin{array}{l}\text { Gbohua- } \\
\text { Angbavia }\end{array}$ & $\begin{array}{l}\text { Tafissou- } \\
\text { Bringakro }\end{array}$ & $\begin{array}{c}\text { N'Da Dibykro-N'Da } \\
\text { Kouassikro }\end{array}$ & $\begin{array}{l}\text { Alluminankro- } \\
\text { N'Kloidjo }\end{array}$ & $\begin{array}{l}\text { Gbakokro- } \\
\text { Abokro }\end{array}$ & \\
\hline Number of households & 245 & 158 & 127 & 120 & 67 & 717 \\
\hline Number of children $\leq 5$ years & 256 & 320 & 175 & 159 & 81 & 991 \\
\hline Houses without cement bricks (\%) & 56.2 & 50.7 & 31.3 & 55.7 & 0 & 43.1 \\
\hline Roof with thatched-grass (\%) & 16.8 & 23.6 & 11.6 & 23.5 & 6.1 & 17.4 \\
\hline Illiteracy rate (\%) & 64.1 & 53.3 & 53.8 & 62.1 & 46.2 & 58.1 \\
\hline \multicolumn{7}{|l|}{$\begin{array}{l}\text { Protective measures against } \\
\text { mosquito bites }\end{array}$} \\
\hline Nets coverage rate (\%) & 2.5 & 3.6 & 2.4 & 7.2 & 1.6 & 3.2 \\
\hline Fumigating coils (\%) & 55.9 & 17.0 & 36.7 & 14.6 & 3.8 & 28.0 \\
\hline Use of insecticide sprays (\%) & 13.2 & 14.2 & 8.7 & 22.5 & 19.2 & 15.2 \\
\hline No protective measure & 21.9 & 51.7 & 43.9 & 46.5 & 60.8 & 43.2 \\
\hline \multicolumn{7}{|l|}{ Preferred colour of bed net } \\
\hline Blue (\%) & 46.9 & 44.4 & 48.4 & 38.9 & 57.7 & 45.3 \\
\hline Green (\%) & 24.7 & 22.1 & 22.6 & 37.8 & 15.4 & 22.8 \\
\hline White (\%) & 21.1 & 7.9 & 10.1 & 3.8 & 3.8 & 12.1 \\
\hline Other colours & 3.2 & 13.7 & 8.8 & 9.6 & 13.2 & 9.6 \\
\hline Don't know & 4.1 & 11.9 & 10.1 & 9.9 & 9.9 & 10.2 \\
\hline \multicolumn{7}{|l|}{$\begin{array}{l}\text { Contribution to pay for a LLIN (in F } \\
\text { CFA) }\end{array}$} \\
\hline$<1000(\%)$ & 1.8 & 4.2 & 23.4 & 1.6 & 6.5 & 7.5 \\
\hline $1000(\%)$ & 97.2 & 82.7 & 62.1 & 50.4 & 88.5 & 77.1 \\
\hline $1500(\%)$ & 1.0 & 11.1 & 9.1 & 37.8 & 3.8 & 12.4 \\
\hline$>1500(\%)$ & 0.0 & 2.0 & 5.4 & 10.2 & 1.2 & 3.8 \\
\hline \multicolumn{7}{|l|}{ Preferred shape of LLINs } \\
\hline Rectangular (\%) & 55.1 & 76.4 & 55.6 & 67.3 & 88.5 & 64.1 \\
\hline Cylindrical (\%) & 41.8 & 13.1 & 18.2 & 11.4 & 7.7 & 23.4 \\
\hline Conical (\%) & 3.1 & 10.5 & 26.2 & 21.3 & 3.8 & 12.5 \\
\hline Convinced of LLINs efficacy (\%) & 93.5 & 92.2 & 72.2 & 57.9 & 46.2 & 84.7 \\
\hline
\end{tabular}

With regard to malaria symptoms, fever was clearly the most important one, followed by loss of appetite, tiredness, abdominal discomfort and diarrhoea. Additionally, yellow eyes and yellow urine were frequently mentioned. Modern health care providers interviewed moreover indicated constipation, diarrhoea, nausea, body aches and pains.

Traditional medicine is primarily sought when a malaria episode occurs. Modern drugs were used to a lesser extent, often simultaneously with traditional medicine.

Impregnation of untreated nets, sensitization and training activities

A total of $11 \mathrm{CHWs}$ in the five study villages were trained on malaria transmission, preventives measures against mosquito bites and the management of uncomplicated malaria cases among children aged 6-59 months.

With the support of SMI, CHWs were trained in the treatment of old nets. CHWs also served as intermediates between the health services and the community, and they were responsible for providing advice to mothers and caregivers of under- 5 year-old children on how to manage uncomplicated malaria cases.

Following the sale of LLINs to household members, CHWs assisted in the installation of the LLINs. Fourteen months after net distribution, the proportions of children below the age of 5 years who slept under a LLIN were $47.3 \%, 56.4 \%, 51.1 \%, 55.4 \%$ and $50.2 \%$ in the villages of All-N'Kl, Gba-Abo, N'Da-N'Da, Taf-Bri and Gbo-Ang, respectively. Table 2 summarises the increase in net usage in young children during LLIN promotion 
Table 2 Proportions of children under the age of 5 years who slept under a LLIN the night before a questionnaire survey in four cross-sectional surveys carried out between April 2007 and November 2008 (in bracket the number of children surveyed), in five villages in central Côte d'Ivoire

\begin{tabular}{|c|c|c|c|c|}
\hline \multirow[t]{2}{*}{ Study sites } & \multicolumn{4}{|c|}{ Proportions of children $<5$ years old sleeping under a LLIN } \\
\hline & April 2007 & November 2007 & April 2008 & November 2008 \\
\hline Gbohua-Angbavia & 2.7 (169) & $17.6(174)$ & $35.7(81)$ & $50.2(125)$ \\
\hline Gbakokro-Abokro & n.a & $18.9(108)$ & n.a & $56.4(69)$ \\
\hline Tafissou-Bringakro & $3.6(262)$ & $19.4(192)$ & $37.9(166)$ & $55.4(146)$ \\
\hline N’Da Dibykro-N'Da Kouassikro & $2.4(143)$ & $16.2(129)$ & $34.5(111)$ & $51.1(117)$ \\
\hline Alluminankro-N'Kloidjo & $7.2(129)$ & $17.3(110)$ & $33.6(95)$ & $47.3(92)$ \\
\hline Overall & $3.5(506)$ & $17.9(453)$ & $36.0(713)$ & $52.1(549)$ \\
\hline
\end{tabular}

campaigns in the study villages from April 2007 (baseline) to November 2008 .

\section{Malaria parasite infection rates}

$P$. falciparum was clearly the predominant malaria parasite in the study villages. Its frequency among positive blood films obtained during the repeated cross-sectional surveys was above $87 \%$. Single species infections with $P$. malariae were found in 3.7-6.2\% of the positive slides. Mixed species infections with $P$. falciparum and $P$. malariae ranged between $1.2 \%$ and $3.8 \%$. Neither $P$. ovale nor $P$. vivax single infections were diagnosed throughout the study. The annual gametocyte rates ranged between $2.4 \%$ and $3.7 \%$.

\section{Plasmodium falciparum prevalence rates}

Table 3 summarises the results of the $P$. falciparum prevalence (number of positive children/number of children examined) obtained during repeated crosssectional surveys carried out between April 2007 and November 2008, in the five study villages among children aged 6-59 months. The data revealed that the prevalence of $P$. falciparum was high in November 2007 and 2008 (during the short rainy season) and low in April 2007 and 2008 (beginning of the long rainy season).
An overall significant decrease in the $P$. falciparum prevalence occurred from April 2007 to April 2008 ( $\mathrm{p}=$ $0.029)$, although it was noted that the rate increased in this period in one of the study villages (Gbo-Ang). An opposite trend was observed from November 2007 to November 2008; P. falciparum prevalence rate increased significantly $(\mathrm{p}=0.003)$, with consistent increases observed in each of the five villages.

Proportion of high parasitaemia and use of LLINs

Table 4 summarises the proportion of high parasitaemia (> 5000 parasites/ $\mu$ l blood) between children who slept under a LLIN and those who did not in the night before the survey, stratified by study village.

Sleeping under a LLIN did not have any effect on the proportion of high parasitaemia in the study villages. Indeed, the differences between the proportions of high parasitaemia recorded among children who slept under a LLIN and those who did not in the night before the survey showed no statistical significance: All-N'Kl ( $\mathrm{p}=$ 0.246), Gba-Abo ( $p=0.084)$, N'Da-N'Da ( $p=0.365)$, Taf-Bri ( $\mathrm{p}=0.953)$ and Gbo-Ang $(\mathrm{p}=0.111)$.

Proportions of fever cases found to be positive for $P$. falciparum

Table 5 summarises the proportion of fever cases found to be positive for $P$. falciparum after blood examination

Table 3 Plasmodium falciparum prevalence rates (95\% confidence interval) and number of children examined per village (in bold), recorded during repeated cross-sectional surveys carried out between April 2007 and November 2008 in five study villages in central Côte d'Ivoire

\begin{tabular}{|c|c|c|c|c|}
\hline \multirow[t]{3}{*}{ Study sites } & \multicolumn{4}{|c|}{ Malaria parasitaemia prevalences $(95 \% \mathrm{Cl})^{\dagger}$} \\
\hline & \multicolumn{2}{|c|}{ April } & \multicolumn{2}{|c|}{ November } \\
\hline & 2007 & 2008 & 2007 & 2008 \\
\hline Gbohua-Angbavia & $45.6(41.1-50.0) / \mathbf{1 6 9}$ & $54.3(45.2-63.5) / 81$ & $62.6(58.5-66.8) / \mathbf{1 7 4}$ & $74.4(68.9-79.9) / \mathbf{1 2 5}$ \\
\hline Gbakokro-Abokro & \multicolumn{2}{|c|}{ n.a } & $70.0(68.9-71.1) / \mathbf{1 0 8}$ & $88.1(83.7-92.6) / 69$ \\
\hline Tafissou-Bringakro & $47.7(45.1-50.3) / 262$ & $25.3(20.7-29.9) / \mathbf{1 6 6}$ & $62.0(57.6-66.4) / \mathbf{1 9 2}$ & $82.9(78.3-87.4) / \mathbf{1 4 6}$ \\
\hline N’Da Dibykro-N’Da Kouassikro & $28.7(25.5-31.9) / \mathbf{1 4 3}$ & $17.1(12.8-21.4) / \mathbf{1 1 1}$ & $52.7(48.2-57.2) / \mathbf{1 2 9}$ & $59.0(53.8-64.2) / \mathbf{1 1 7}$ \\
\hline Alluminankro-N'Kloidjo & $57.8(54.5-61.1) / \mathbf{1 2 9}$ & $17.9(12.9-22.9) / 95$ & $55.5(50.2-60.7) / \mathbf{1 1 0}$ & $90.2(86.2-94.2) / \mathbf{9 2}$ \\
\hline \multirow[t]{2}{*}{ Overall } & $45.3(43.6-47.0) / 506$ & $26.9(24.2-29.7) / 453$ & $60.2(58.3-62.3) / 713$ & $77.6(75.3-79.8) / 549$ \\
\hline & \multicolumn{2}{|c|}{ April 2007 vs. April 2008: $p=0.029^{\ddagger}$} & \multicolumn{2}{|c|}{ November 2007 vs. November 2008: $p=0.003^{\ddagger}$} \\
\hline
\end{tabular}

n.a: not assessed + : finite population corrected $\neq$ : adjusted for cluster sampling design. 
Table 4 Proportion of children less than 5 years old with high parasitaemia levels (> 5000 parasites/ $\mu$ l blood; in brackets number of high parasitaemia out of the number of children examined), observed during repeated crosssectional surveys carried out between April 2007 and November 2008 in five study villages in central Côte d'lvoire

\begin{tabular}{llll}
\hline Study sites & Periods of surveys carried out & & P-value \\
\hline & Sleeping under a LLIN & Not sleeping under a LLIN & 0.084 \\
Gbohua-Angbavia & $4.0(11 / 275)$ & $7.7(21 / 274)$ & 0.111 \\
Gbakokro-Abokro & $13.0(13 / 100)$ & $5.2(4 / 77)$ & 0.953 \\
Tafissou-Bringakro & $5.7(24 / 424)$ & $5.6(19 / 342)$ & 0.115 \\
N'Da Dibykro-N'Da Kouassikro & $2.9(7 / 236)$ & $6.1(16 / 264)$ & 0.365 \\
Alluminankro-N'Kloidjo & $4.6(10 / 218)$ & $6.7(14 / 208)$ & 0.246 \\
Total & $5.2(65 / 1253)$ & $6.3(74 / 1165)$ & \\
\hline
\end{tabular}

(clinical malaria cases). A highly significant fall in clinical malaria rates was observed both between April 2007 and April 2008 ( $\mathrm{p}<0.001$ ), and between November 2007 and November $2008(\mathrm{p}=0.001)$. These trends were reflected in all five villages.

\section{Discussion}

The increase recorded in Plasmodium prevalence rate from November 2007 to November 2008 could be explained by the fact that during the latter period, conditions such as rainfall and humidity were more conducive to mosquito development. Generally, when environmental conditions are favourable (monthly rainfall up to 150 mm and humidity around $85 \%$ ), more productive $A n$. gambiae breeding sites are formed, contributing to the increase of Plasmodium infection [18]. Previous studies carried out in sub-Saharan Africa, in areas of stable malaria characterized by high EIRs, showed that the protective efficacy of LLINs was lower [2]. The reduction recorded in LLIN protective efficacy is confirmed by the fact that several studies performed in three malaria stable West African countries (Ghana, Côte d'Ivoire and Burkina Faso) reported very low reduction on Plasmodium prevalence rate $(13 \%$ reduction when the control group did not have any nets and 10\% reduction when the control group had untreated nets) [19-21]. Increased records in Plasmodium prevalence rate could also be due to the fact that LLINs were not properly used by householders, specifically because we recorded a reduction in malaria transmission in April and July 2008, 9 months after net distribution (unpublished data). During this low transmission and biting period, the perceived benefits of reduction in mosquito bites and of malaria were considered not to be important by household members. Recent studies carried out in Burkina Faso [22] showed that LLINs were not used during the dry season (period of low biting rates) and when the perceived benefits of reduction in mosquitoes bites and of malaria were considered not to be important, even during the high transmission period. Additionally, both studies have shown that the usefulness of LLINs in reducing malaria prevalence rate and morbidity was moderated by the fact that mosquitoes were considered to be only one of several factors which caused malaria [22].

From April 2007 to April 2008, a statistically significant reduction was observed in the overall Plasmodium infection rates recorded among children aged between 6 and 59 months. Indeed, activities carried out few

Table 5 Percentage of children less than 5 years old examined positive after blood examination (number of positive fever cases/number of children examined), and number of children examined per village (in bold), recorded during repeated cross-sectional surveys carried out between April 2007 and November 2008 in five study villages in central Côte d'Ivoire

\begin{tabular}{|c|c|c|c|c|}
\hline \multirow[t]{3}{*}{ Study sites } & \multicolumn{4}{|c|}{ Proportions of clinical malaria cases $(95 \% \mathrm{Cl})^{\dagger}$} \\
\hline & \multicolumn{2}{|c|}{ April } & \multicolumn{2}{|c|}{ November } \\
\hline & 2007 & 2008 & 2007 & 2008 \\
\hline Gbohua-Angbavia & $17.2(13.8-20.5) / 169$ & $3.6(0.2-7.0) / 81$ & $12.5(9.8-15.4) / 174$ & $5.6(2.7-8.4) / 125$ \\
\hline Gbakokro-Abokro & \multicolumn{2}{|c|}{ n.a } & $6.3(5.6-6.9) / 108$ & $3.3(1.0-5.7) / 69$ \\
\hline Tafissou-Bringakro & $18.3(16.3-20.2) / 262$ & $6.3(3.6-9.1) / 166$ & $10.4(7.7-13.2) / 192$ & $8.3(4.9-11.6) / 146$ \\
\hline N’Da Dibykro-N'Da Kouassikro & $9.8(7.7-11.9) / 143$ & $4.5(2.1-6.8) / 111$ & $19.4(15.8-22.9) / 129$ & $8.3(5.1-11.6) / 117$ \\
\hline Alluminankro-N'Kloidjo & $8.1(6.3-10.0) / 129$ & $5.3(0.2-8.2) / 95$ & $13.6(10.0-17.3) / 110$ & $10.6(6.6-14.7) / 92$ \\
\hline \multirow[t]{2}{*}{ Overall } & $14.4(13.2-15.6) / 506$ & $5.1(3.7-6.5) / 453$ & $12.7(11.3-14.0) / 713$ & $7.5(6.0-9.0) / 549$ \\
\hline & \multicolumn{2}{|c|}{ April 2007 vs. April 2008: $p<0.001^{\ddagger}$} & \multicolumn{2}{|c|}{ November 2007 vs. November 2008: $p=0.001^{\ddagger}$} \\
\hline
\end{tabular}

n.a: not assessed + : finite population corrected $\neq$ : adjusted for cluster sampling design. 
months after net distribution by CHWs and mass sensitization campaigns undertaken in the study villages contributed to reduce drastically Plasmodium prevalence rate. It is conceivable that the motivation for the use of LLINs is high shortly after mass and household-tohousehold sensitization campaigns. This argument is confirmed by a recent study carried out in Burkina Faso showing that the motivation for the use of LLINs decreased after less than a year [22]. The increase in motivation for the use of LLINs could also be explained by the fact that nets were distributed during the short rainy season (from mid-September to mid-November), at a time An. gambiae biting rates are supposed to be high. During this study period, particularly in April, during the rainy season, previous studies carried out in three urban cities of West Africa (Abidjan, Cotonou and Ouagadougou) showed that sleeping under an ITN the night before the survey was protective against Plasmodium infection [23-25]. Additionally, a recent study showed that Plasmodium prevalence rate was strongly influenced by socioeconomic status, and the methods used for prevention depended on their perceived cost [26]. In our study, however, no link was found between the proportion of protective measures and Plasmodium infection rates, perhaps because in villages where we recorded the highest Plasmodium infection rates, the use of fumigating coils and insecticides was high.

Another important finding of our study is that we observed a significant decrease in the overall proportions of clinical malaria cases among children less than 5 years old during both study periods, from April 2007 to April 2008 and from November 2007 to November 2008. This observation might be explained by the considerable number of household members sleeping under LLINs instigated by the household-to-household and mass sensitization campaigns undertaken before and after net distribution. Of note, in this project, although the price of nets was relatively low, we did not carry out free distribution of nets. Similarly, in Tanzania, 10 years ago, social marketing of treated nets was identified as an effective means for malaria control in rural settings. Eighteen months after launching promotion of treated nets, $46 \%$ of 312 families with children aged less than 5 years reported that their children were sleeping under treated nets [8]. In a demographic surveillance system area of Tanzania, after a social marketing campaign, ITN coverage of infants rose from $<10 \%$ at baseline to $>50 \%$ some 3 years later. Treated nets were associated with a $27 \%$ increase in survival in children aged 1 month to 4 years [9]. A reduction in the number of clinical malaria cases was also recorded in Kafine, a village located in the northern rice-growing region of Côte d'Ivoire, where the main malaria vector, An. gambiae s. $s$., is resistant to permethrin and other pyrethroids [20].
In this village, the rate of malaria attacks was twice as high among non-users of mosquito nets. Meanwhile, previous studies performed in several West African malaria stable countries (Côte d'Ivoire, Gambia and Sierra Leone), the differences in treated nets protective efficacies against uncomplicated malaria were low (11\%) $[20,27,28]$.

Finally, in our study, no significant statistical difference was found between users and non-users of LLINs concerning the prevalence of high parasitaemia levels (> 5000 parasites/ $\mu$ l blood). This observation is in agreement with previous studies carried out in the savannah village of Kafine, northern Côte d'Ivoire, where no difference was found between user and non-user groups of mosquito nets with regard to the prevalence of high parasitaemia, or gametocytes or to the mean parasite load [20]. Generally, in a highly endemic area, there is no marked variation in malaria prevalence rates and morbidity during the season of high prevalence rate. Indeed, in some previous studies performed in East Africa treated nets did not appear to reduce malaria prevalence rate, parasite density and all cause morbidity $[29,30]$. Conversely, treated nets have proved to have a significant protective efficacy against high parasitaemia in Kenya among children less than 5 years [31].

To conclude, training and sensitization activities undertaken before and after net distribution contributed to reducing Plasmodium prevalence from April 2007 to April 2008 and to significantly reducing the number of clinical malaria cases. However, 8-9 months after net distribution, a decrease in the motivation for the use of nets probably favoured a significant increase in the overall Plasmodium prevalence rate from November 2007 to November 2008. Thus, continued long-term social marketing for promoting LLINs holds promise for effective malaria control in rural and urban malaria endemic countries.

\section{Acknowledgements}

Our thanks are addressed to the village authorities, villagers, the health district officers and the nurse of the five study villages Tafissou-Bringakro, Gbohua-Angbavia, Alluminankro-N'Kloidjo, N'Da Dibykro-N'Da Kouassikro, Gbakokro-Abokro, belonging to the health district of Toumodi. This investigation received financial support from a private donation made to the London School of Hygiene and Tropical Medicine. While this project was carried out, BGK was partially supported by the Swiss Tropical and Public Health Institute.

\section{Author details}

${ }^{1}$ Vector Group, Liverpool School of Tropical Medicine, Pembroke Place, Liverpool L3 5QA, UK. ${ }^{2}$ Centre Suisse de Recherches Scientifiques en Côte d'Ivoire, 01 BP 1303, Abidjan 01, Côte d'Ivoire. ${ }^{3}$ UFR Sciences de Nature, Université d'Abobo-Adjamé, 02 BP 801, Abidjan 02, Côte d'Ivoire. ${ }^{4} \mathrm{MRC}$ International Nutrition Group, London School of Hygiene and Tropical Medicine, Keppel Street, London WC1E 7HT, UK. ${ }^{5}$ Department of Nutrition and Food Sciences, American University of Beirut, P.O. Box 11-0236, Beirut 1107 2020, Lebanon. 'Institut d'Ethno Sociologie, Université de CocodyAbidjan, 01 BP V34, Abidjan 01, Côte d'Ivoire. 7Department of Epidemiology 
and Public Health, Swiss Tropical and Public Health Institute, P.O. Box, CH4002 Basel, Switzerland. ${ }^{8}$ University of Basel, P.O. Box, CH-4003 Basel, Switzerland. ${ }^{9}$ Institute of Food, Nutrition, and Health, Swiss Federal Institute of Technology Zurich, $\mathrm{CH}-8092$ Zurich, Switzerland. ${ }^{10} \mathrm{Clinical}$ Group, Liverpool School of Tropical Medicine, Pembroke Place, Liverpool L3 5QA, UK.

\section{Authors' contributions}

BGK: designed experiments, coordinated field activities, collected and analyzed data, wrote and revised the paper; HG: designed the study and participated in the coordination of the field activities; CE: designed experiments, collected data and analysed socio-anthropological data; $\mathrm{CN}$ : contributed to the study design and revised the paper; FR: designed the study, participated in the coordination of field activities and revised the paper; JU: participated in the design of the study and revised the paper; BEF: assisted with the statistical analysis and revised the paper; ABT: designed the study, participated in the coordination of field activities and revised the paper. All authors have read and agreed with the content of the submitted manuscript.

\section{Competing interests}

The authors declare that they have no competing interests.

Received: 12 August 2010 Accepted: 22 September 2010 Published: 22 September 2010

\section{References}

1. Anonymous: Programme National de Lutte contre le Paludisme, Côte d'Ivoire. Ministère de la Santé Publique 2001.

2. Lengeler $C$ : Insecticide-treated bed nets and curtains for preventing malaria. Cochrane Database Syst Rev 2009, , 2: CD000363.

3. WHO: World malaria report 2009. 2009, 78[http://www.who.int/malaria/ world_malaria_report_2009/en/index.html].

4. Noor AM, Mutheu JJ, Tatem AJ, Hay SI, Snow RW: Insecticide-treated net coverage in Africa: mapping progress in 2000-07. Lancet 2009, 373:58-67.

5. Erlanger TE, Enayati AA, Hemingway J, Mshinda $H$, Tami A, Lengeler C: Field issues related to effectiveness of insecticide-treated nets in Tanzania. Med Vet Entomol 2004, 18:153-160.

6. Phillips-Howard PA, Ruebush TK, Oloo AJ, Nahlen BL: Maintenance and sustained use of insecticide-treated bednets and curtains three years after a controlled trial in western Kenya. Trop Med Int Health 1999, 4:728-735.

7. WHO: Report of the sixth meeting of the global collaboration for development of pesticides for public health. WHO/CDS/WHOPES/GCDPP/ 2008.4 Geneva, World Health Organization 2008.

8. Armstrong Schellenberg JRM, Abdulla S, Minja H, Nathan R, Mukasa O, Marchant T, Mponda H, Kikumbih N, Lyimo E, Manchester T, Tanner M, Lengeler C: KINET: a social marketing programme of treated nets and net treatment for malaria control in Tanzania, with evaluation of child health and long-term survival. Trans R Soc Trop Med Hyg 1999, 93:225-231.

9. Armstrong Schellenberg JRM, Abdulla S, Nathan R, Mukasa O, Marchant TJ Kikumbih N, Mushi AK, Mponda H, Minja H, Mshinda H, Tanner M, Lengeler C: Effect of large-scale social marketing of insecticide-treated nets on child survival in rural Tanzania. Lancet 2001, 357:1241-1247.

10. Hanson K, Kikumbih N, Armstrong Schellenberg J, Mponda H, Nathan R, Lake S, Mills A, Tanner M, Lengeler C: Cost-effectiveness of social marketing of insecticide-treated nets for malaria control in the United Republic of Tanzania. Bull World Health Organ 2003, 81:269-276.

11. Rohner F, Zimmermann MB, Amon RJ, Vounatsou P, Tschannen AB, N'Goran EK, Nindjin C, Cacou MC, Té-Bonlé MD, Aka H, Sess DE, Utzinger J, Hurrell RF: In a randomized controlled trial of iron fortification, anthelmintic treatment, and intermittent preventive treatment of malaria for anemia control in Ivorian children, only anthelmintic treatment shows modest benefit. J Nutr 2010, 140:635-641.

12. Ouattara FA: Effets de l'utilisation des moustiquaires imprégnées d'insecticide de longue durée sur la transmission de Plasmodium au centre de la Côte d'Ivoire. Diplôme d'Etudes Approfondies (DEA), Université de Bouake, Côte d'Ivoire 2009.
13. Dossou-Yovo J, Doannio JM, Rivière F, Chauvancy G: Malaria in Côte d'Ivoire wet savannah region: the entomological input. Trop Med Parasitol 1995, 46:263-269.

14. Koudou BG, Tano Y, Doumbia M, Nsanzabana C, Cissé G, Girardin O, Dao D, N'Goran EK, Vounatsou P, Bordmann G, Keiser J, Tanner M, Utzinger J: Malaria transmission dynamics in central Côte d'Ivoire: the influence of changing patterns of irrigated rice agriculture. Med Vet Entomol 2005, 19:27-37.

15. Koudou BG, Tano Y, Keiser J, Vounatsou P, Girardin O, Kouassi K, Koné M, N'Goran EK, Cissé G, Tanner M, Utzinger J: Effect of agricultural activities on prevalence rates, and clinical and presumptive malaria episodes in central Côte d'Ivoire. Acta Trop 2009, 111:268-274.

16. Koudou BG, Doumbia M, Janmohamed N, Tschannen AB, Tanner M, Hemingway J, Utzinger J: Effects of seasonality and irrigation on malaria transmission in two villages in Côte d'Ivoire. Ann Trop Med Parasitol 2010, 104:109-121.

17. Smith T, Armstrong-Schellenberg J, Hayes R: Attributable fraction estimates and case definitions for malaria in endemic areas. Stat Med 1994, 13:2345-2358.

18. Dossou-Yovo J: Etude ethiologique des moustiques vecteurs du paludisme en rapport avec les aspects parasitologiques de la transmission du plasmodium dans la Region de Bouaké. These de Doctorat d'Etat en Entomologie Medicale, Université de Cocody, Abidjan 2000.

19. Binka FN, Hodgson A, Adjuik M, Smith T: Mortality in a seven and-a-halfyear follow-up of a trial of insecticide-treated mosquito nets in Ghana. Trans R Soc Trop Med Hyg 2002, 96:597-599.

20. Henry MC, Doannio JMC, Darriet F, Nzeyimana I, Carnevale P: Effcacité des moustiquaires pre-imprégnées de permethrine Olyset Netq en zone de résistance des vecteurs aux pyrethrinoides. II. Evaluation parasiteclinique. Med Trop 1999, 59:355-357.

21. Essé C, Utzinger J, Tschannen AB, Raso G, Pfeiffer C, Granado S, Koudou BG, N'Goran EK, Cissé G, Girardin O, Tanner M, Obrist B: Social and cultural aspects of 'malaria' and its control in central Côte d'Ivoire. Malar J 2008, $7: 224$

22. Toé LP, Skovmand O, Dabiré KR, Diabaté A, Diallo Y, Guiguemdé TR, Doannio JM, Akogbeto M, Baldet T, Gruénais ME: Decreased motivation in the use of insecticide-treated nets in a malaria endemic area in Burkina Faso. Malar J 2009, 8:175

23. Wang SJ, Lengeler C, Smith TA, Vounatsou P, Cissé G, Tanner M: Rapid urban malaria appraisal (RUMA) III: epidemiology of urban malaria in the municipality of Yopougon (Abidjan). Malar J 2006, 5:29.

24. Wang SJ, Lengeler C, Smith TA, Vounatsou P, Diadie DA, Pritroipa X, Convelbo N, Kienga M, Tanner M: Rapid urban malaria appraisal (RUMA) I: Epidemiology of urban malaria in Ouagadougou. Malar J 2005, 4:43.

25. Wang SJ, Lengeler C, Smith TA, Vounatsou P, Akogbeto M, Tanner M: Rapid urban malaria appraisal (RUMA) IV: Epidemiology of urban malaria in Cotonou (Benin). Malar J 2006, 5:45.

26. Samuelsen $H$, Toé $L P$, Baldet $T$, Skovmand O: Prevention of mosquito nuisance among urban populations in Burkina Faso. Soc Sci Med 2004, 59:2361-2371.

27. Snow RW, Rowan KM, Lindsay SW, Greenwood BM: A trial of bed nets (mosquito nets) as a malaria control strategy in a rural area of The Gambia, West Africa. Trans R Soc Trop Med Hyg 1988, 82:212-215.

28. Marbiah NT, Petersen E, David K, Magbity E, Lines J, Bradley DJ: A controlled trial of lambda-cyhalothrin-impregnated bed nets and/or dapsone/pyrimethamine for malaria control in Sierra Leone. Am J Trop Med Hyg 1998, 58:1-6.

29. Friedman JF, Phillips-Howard PA, Hawley WA, Terlouw DJ, Kolczak MS, Barber M, Okello N, Vulule JM, Duggan C, Nahlen BL, ter Kuile FO: Impact of permethrin-treated bed nets on growth, nutritional status, and body composition of primary school children in western Kenya. Am J Trop Med Hyg 2003, 68:78-85.

30. Van Bortel W, Delacollette C, Barutwanayo M, Coosemans M: Deltamethrinimpregnated bed nets as an operational tool for malaria control in a hyper-endemic region of Burundi: impact on vector population and malaria morbidity. Trop Med Int Health 1996, 1:824-835. 
31. Phillips-Howard PA, Nahlen BL, Kolczak MS, Hightower AW, ter Kuile FO, Alaii JA, Gimnig JE, Arudo J, Vulule JM, Odhacha A, Kachur SP, Schoute E, Rosen DH, Sexton JD, Oloo AJ, Hawley WA: Efficacy of permethrin treated bed nets in the prevention of mortality in young children in an area of high perennial malaria transmission in western Kenya. Am J Trop Med Hyg 2003, 68:23-29.

doi:10.1186/1756-3305-3-91

Cite this article as: Koudou et al.: The use of insecticide-treated nets for reducing malaria morbidity among children aged 6-59 months, in an area of high malaria transmission in central Côte d'Ivoire. Parasites \& vectors 2010 3:91.

Submit your next manuscript to BioMed Central and take full advantage of:

- Convenient online submission

- Thorough peer review

- No space constraints or color figure charges

- Immediate publication on acceptance

- Inclusion in PubMed, CAS, Scopus and Google Scholar

- Research which is freely available for redistribution

Submit your manuscript at www.biomedcentral.com/submit
C Biomed Central 